\title{
A re-evaluation of sperm ultrastructure in the emu, Dromaius novaehollandiae
}

\author{
Lizette du Plessis ${ }^{1 *}$ and John T Soley ${ }^{2}$
}

\begin{abstract}
${ }^{1}$ Electron Microscope Unit, Department of Anatomy and Physiology, Faculty of Veterinary Science, University of Pretoria, Onderstepoort 0110, South Africa

${ }^{2}$ Department of Anatomy and Physiology, Faculty of Veterinary Science, University of Pretoria, Onderstepoort 0110, South Africa
\end{abstract}

*Corresponding author. Tel.: p27 12 5298212; fax: p27 12 5298320. E-mail address: lizette.duplessis@up.ac.za (L. du Plessis).

\begin{abstract}
Existing reports on sperm structure in the emu do not adequately illustrate or describe all the salient ultrastructural features necessary for a meaningful comparison of normal and abnormal sperm in this species. As sperm morphology forms an important parameter in determining semen quality, and in view of the proposed role of artificial insemination in the farming of ratites, this paper re-evaluates and complements the existing data on the topic, provides a fully illustrated description of emu sperm ultrastructure and documents some unreported morphological features. Conventional transmission (TEM) and scanning (SEM) electron microscopy, as well as high resolution SEM, was used to describe the ultrastructure of sperm harvested from the distal deferent duct of sexually mature birds slaughtered during the breeding season. In addition to broadly confirming the basic ultrastructural characteristics previously described for emu sperm, this study revealed a number of unreported morphological features. These included distinct differences in surface properties between the acrosome and nucleus, the presence of a thread-like appendage near the base of the nucleus, variable positioning of the annulus relative to structures located at the midpiece - principal
\end{abstract}


piece junction and regional differentiation of the principal piece. Although the emu displayed similar basic morphological features to sperm of other ratites and the tinamou, marked structural peculiarities were obvious, notably the lack of an endonuclear canal and a perforatorium as well as the presence of significantly more mitochondria in the midpiece coupled with an absence of inter-mitochondrial cement. Whereas the broad morphological features of emu sperm would appear to add credence to the general view that the ratites, together with the tinamous, form a monophyletic group at the base of the avian phylogenetic tree, it is also clear that emu sperm are distinctly different from those of the ostrich, rhea and tinamou which together share morphological affinities This observation may lend some support to the alternate view that the Australasian ratites represent a separate clade that developed independently from flightless ancestors.

Keywords: emu, Dromaius novaehollandiae, sperm morphology, ultrastructure

\section{Introduction}

In common with other niche industries such as ostrich and crocodile farming, the commercial raising of emus is a relatively small enterprise and is severely hampered by high production costs and the vagrancies of global economic conditions. The ratite industry currently relies on natural reproduction, a strategy that is not always cost effective, partly due to the monogamous nature of ratites [1,2]. This means that a large number of male birds must be kept for the sole purpose of breeding, which adds an unnecessary financial burden to farming operations. Males often become aggressive during the breeding season and can cause serious injuries to each other which lead to additional veterinary expenses. In order to address these problems, it has been suggested $[3,4]$ that the ratite industry should employ advanced reproductive technologies such as artificial insemination (AI), which has been successfully 
employed in commercial poultry enterprises [5-7]. Since its inception AI has become an important production tool in the poultry industry, as well as in the conservation of endangered species [8]. For instance, in turkey farming AI has increased fertility by up to $50 \%$ [9]. Although most AI efforts in non-domestic birds have been research orientated [10], the practical and financial benefits of this technique would clearly be of value in niche industries such as emu farming. However, the success of this technique is directly dependent on the quality of the collected semen. The accurate evaluation of semen quality prior to its use in AI programmes is thus of the utmost importance and sperm morphology, together with sperm motility and sperm concentration, has been identified as one of the most important qualitative semen parameters to be considered.

Whereas the ultrastructural features of normal ostrich sperm have been thoroughly described [11-15], only limited information is currently available on the fine structure of emu sperm. Existing data [12] does not adequately illustrate or describe all the salient ultrastructural features of emu sperm necessary for a meaningful comparison of normal and abnormal sperm in this species. This paper re-evaluates and complements the existing data, provides a fully illustrated description of emu sperm ultrastructure and documents some previously unreported morphological features. The results are also compared and discussed in relation to sperm structure in other ratites and non-passerine birds in general.

\section{Materials \& Methods}

Semen samples for transmission (TEM) and scanning electron microscopy (SEM) were collected during mid-breeding season from 15 healthy (animals approved for slaughter) and sexually active emus following slaughter at commercial abattoirs. The birds ranged in age from 22 months to five years. Samples were collected approximately 60 minutes after the 
birds had been slaughtered. Drops of semen were gently squeezed from the distal ductus deferens into test tubes containing $2.5 \%$ glutaraldehyde in $0.13 \mathrm{M}$ Millonig's phosphatebuffer (pH7.4) and fixed overnight at $4^{\circ} \mathrm{C}$. Using gentle centrifugation and re-suspension throughout, the samples were washed in Millonig's phosphate buffer, prior to post-fixation in similarly buffered $1 \%$ osmium tetroxide for one hour. After two subsequent washes in buffer, the samples were dehydrated through a graded ethanol series $(50 \%, 70 \%, 90 \%, 96 \%, 3 \mathrm{x}$ $100 \%$ for 20 minutes each). At this stage samples for TEM were cleared with propylene oxide for 20 minutes and embedded in epoxy resin (TAAB 812 resin; TAAB Laboratories, England). Thin sections were cut with a Reichert-Jung Ultracut (C. Reichart AG., Vienna, Austria) ultramicrotome using a diamond knife and stained with lead citrate and uranyl acetate before being viewed in a Philips CM10 transmission electron microscope (Philips Electron Optical Division, Eindhoven, The Netherlands) operated at $80 \mathrm{kV}$.

After the dehydration steps indicated above, the samples for SEM were incubated in hexamethyldisilazane (HMDS) for $30 \mathrm{~min}$ after which they were centrifuged, the supernatant discarded and the pellets re-suspended in HMDS. A drop of this suspension was placed on a cover slip and allowed to air dry, after which it was sputter-coated with gold and viewed in a JEOL 840 scanning electron microscope (JEOL Electron Optics Instrumentation, Tokyo, Japan) operated at $8 \mathrm{kV}$. Additionally, for each sample a drop of the re-suspended pellet in HMDS was placed on a carbon stub and allowed to air dry. These samples were viewed uncoated at $0.5 \mathrm{kV}$ in a Zeiss Ultra Plus 55 High Resolution FEG scanning electron microscope (Carl Zeiss International, Oberkogen, Germany). 


\section{Results}

\section{Scanning electron microscopy}

Conventional SEM confirmed the basic morphological features of emu sperm previously observed by light microscopy [16] and SEM [12]. The cells were long and narrow and the various segments, namely, the acrosome, nucleus, midpiece, principal piece and endpiece, could be distinguished although the transition was not always clear (Fig. 1). The acrosome formed the anterior tip of the sperm head and, although tapering anteriorly, displayed a blunt, rounded tip (Fig. 1). The base of the acrosome was clearly demarcated from the nucleus which constituted the longest segment of the head. The surface of the head, in particular that of the acrosome, was smooth when viewed by SEM (Fig. 1). The head was often gently curved with the nucleus widening slightly towards its base. In most of the sperm a thin thread-like or wedge-shaped appendage could be seen to extend at right angles from the cell surface in the vicinity of the head base (Fig. 1). However, in some cells the appendage emerged from the proximal aspect of the midpiece.

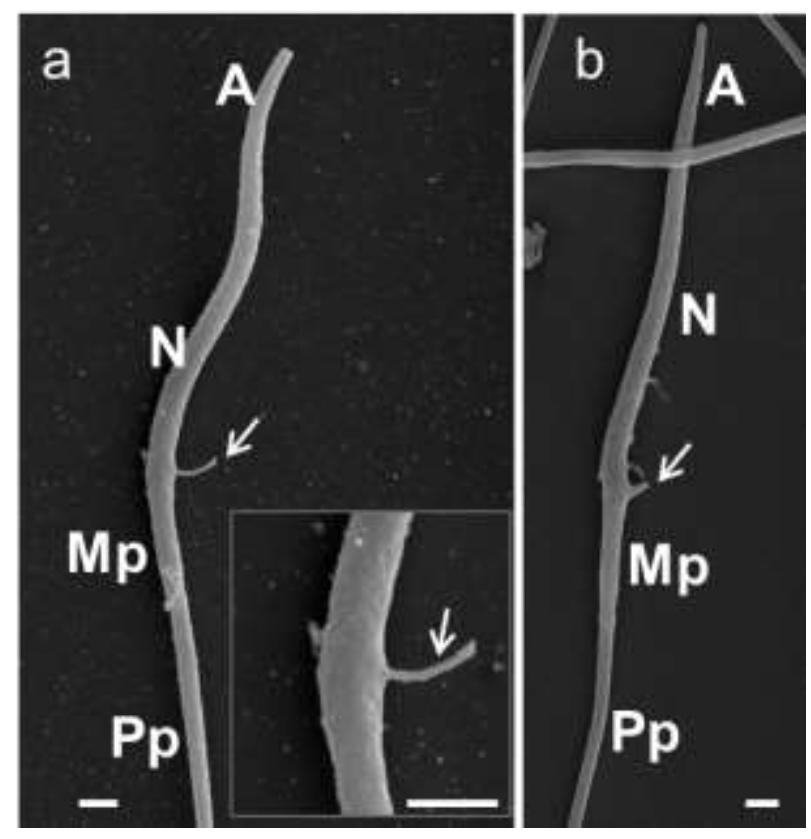

Figure 1. Emu sperm exhibiting the typical single cytoplasmic appendage (arrow) observed by conventional SEM. In (a) and in the inset, the appendage is thread-like, while in (b) it appears as a short, stubby projection. Acrosome $(A)$, nucleus $(\mathrm{N})$, midpiece $(\mathrm{Mp})$, principal piece $(\mathrm{Pp})$. Bar $=1 \mu \mathrm{m}$; inset, $\mathrm{Bar}=1 \mu \mathrm{m}$. 
A distinction could be made between the head and midpiece with the latter appearing roughened presumably due to the presence of the mitochondrial sheath in this region. The midpiece tapered gradually towards the noticeably thinner principal piece. The principal piece formed the longest segment of the sperm and ended abruptly in a thin, short endpiece. Unlike the midpiece, the principal piece and endpiece displayed smooth surface profiles with no distinct surface characteristics (Fig. 1).

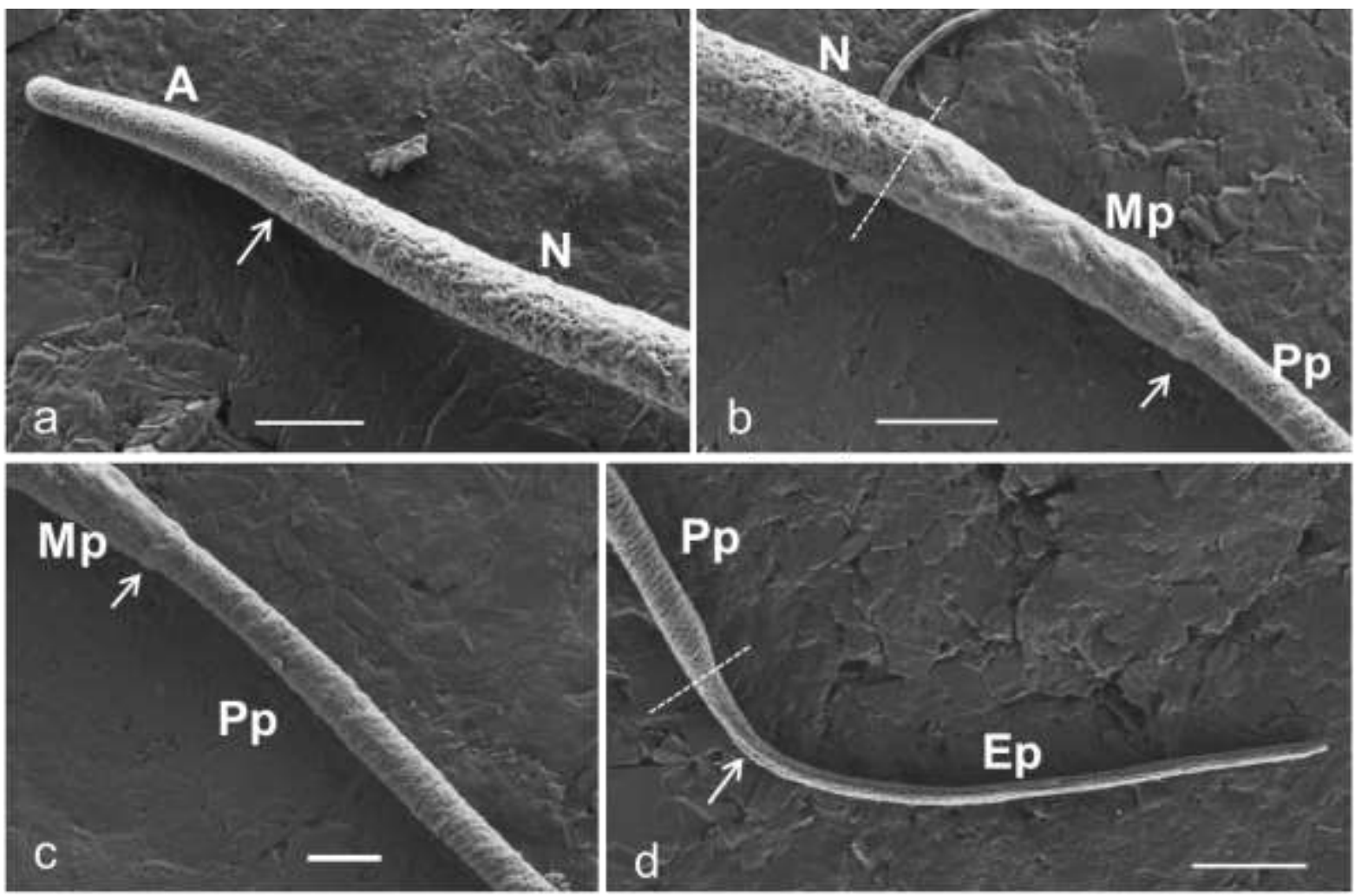

Figure 2. Low kV scanning electron micrographs of the various sperm segments. (a) Note the smooth surface of the acrosome when compared to the rest of the head. An arrow indicates the demarcation between the acrosome and nucleus. (b) The midpiece demonstrating profiles of the mitochondria. The annulus appears as a ring-like structure (arrow), indicating the termination of the midpiece. (c) A section of the principal piece clearly demonstrating the ribs of the fibrous sheath.The annulus is again prominent (arrow). (d) The endpiece is smooth and devoid of a fibrous sheath although some of the underlying microtubules of the axoneme can be visualised (arrow). Acrosome $(A)$, nucleus $(N)$, midpiece $(M p)$, principal piece $(P p)$, endpiece $(\mathrm{Ep})$. Bar $=1 \mu \mathrm{m}$. 
When viewed uncoated and at low $\mathrm{kV}$ using high resolution SEM, the various segments of the sperm could more accurately be discerned than by standard SEM. The acrosome displayed a much smoother surface than the rest of the head which appeared mottled, with a clear junction between the two segments being visible (Fig. 2a). The transition between the sperm head and midpiece was abrupt with the surface features of the two segments appearing markedly different. Mitochondrial profiles could often be seen beneath the plasmalemma in the midpiece, giving the surface of this region a cobbled appearance (Fig. 2b). The midpiece tapered slightly towards its distal end (Fig. 2b). The annulus, which demarcated the transition between the midpiece and principal piece, was particularly obvious using this technique, appearing as a prominent circular band or ring between the two segments (Figs. 2b,c). The ribs of the fibrous sheath were visible throughout the length of the principal piece, and ended abruptly at the transition to the endpiece which displayed smooth contours with a hint of the underlying microtubules of the axoneme (Fig. 2d).

\section{Transmission electron microscopy}

\section{The head:}

Longitudinal sections of sperm examined by TEM confirmed that the apical tip of the highly condensed nucleus extended deep within the acrosome (Fig. 3). The extent to which the nuclear tip penetrated beneath the acrosome varied, depending on the plane of section. The acrosome formed a blunt, cone-like structure covering the tip of the nucleus and was composed of a homogeneous, moderately electron-dense substance. The narrow subacrosomal space between the acrosome and nucleus was often occupied by flocculant, moderately electron-dense material. In some instances this space appeared empty. The nuclear rostrum beneath the acrosome was tapered while the body of the nucleus was cylindrical, widening slightly towards the base. The plasmalemma was tightly attached to the 


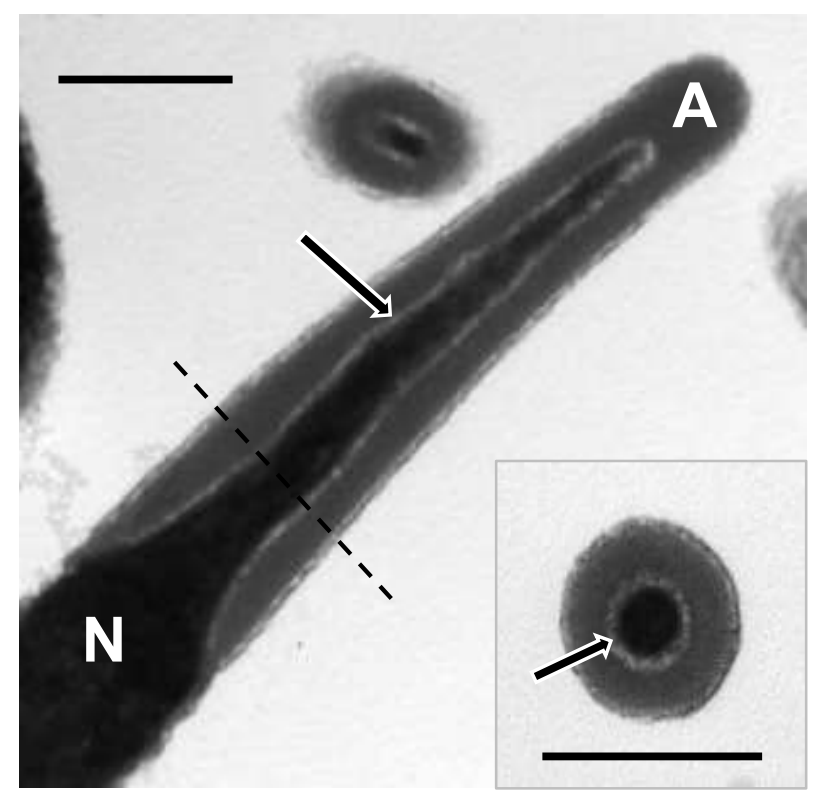

Figure 3. Longitudinal section through the apex of the sperm head showing the conical acrosome (A) covering the tip of the nucleus $(\mathrm{N})$. Inset: Transverse section through the acrosome (at approximately the level of the dotted line in the figure) illustrating the central core of nuclear material surrounded by the acrosome. Note the narrow sub-acrosomal space in both micrographs (arrow). Bars $=0.5 \mu \mathrm{m}$.

entire head (acrosome and nucleus), with a thin intervening layer of cytoplasm which was more obvious towards the nuclear base. The electron-dense nuclear chromatin was homogeneous and tightly compacted, although in some cells there were localized areas that appeared granular or filamentous in nature, presumably representing regions of incomplete or decondensed chromatin. The base of the nucleus terminated in a shallow implantation fossa. No perforatorium or endonuclear canal was present in the emu sperm head.

The thread-like appendage observed on SEM was also noted on TEM in both longitudinal and transverse sections of the head base (Fig. 4). In transverse section the appendage generally appeared as a thin finger-like protrusion at the base of the nucleus, but sometimes formed a small stubby triangle. It was always covered by the plasmalemma and was composed of pale, homogenous material (presumably residual cytoplasm) devoid of cytoplasmic organelles. 

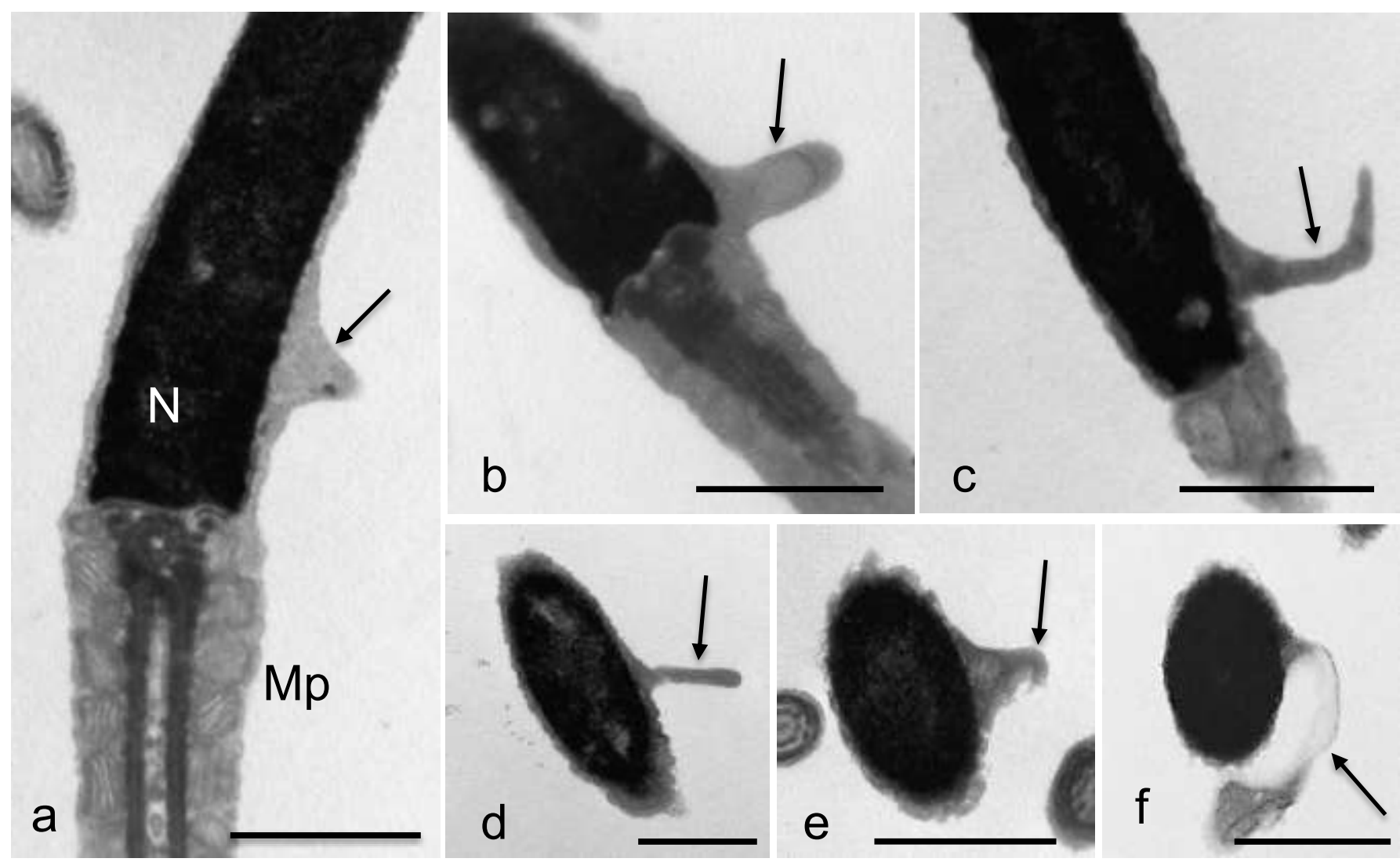

Figure 4. Longitudinal (a-c), oblique (d) and transverse (e-f) sections of sperm demonstrating the cytoplasmic appendage situated at the head base - midpiece region. The appendage varies in shape from short, stubby fingerlike (b); slender finger-like (d); bent (c); club-shaped (f); and triangular (a,e). Nucleus (N), midpiece $(M)$. Bar = $1 \mu \mathrm{m}$.

\section{The neck:}

The neck region (forming the connection between the head and the midpiece) (Fig. 5) displayed a shallow concave implantation fossa at the base of the nucleus lined by a thin layer of moderately electron-dense material, the basal plate. The fossa appeared in the form of individual impressions each housing one of the poorly defined segmented columns that, together with the capitellum, formed the connecting piece. Depending on the plane of section, two shallow impressions were generally observed at the nuclear base (Fig. 5), suggesting that the implantation fossa consisted of a series of depressions running along the perimeter of the nuclear base. The tips of the segmented columns merged to form the capitellum, which was separated from the basal plate by an intervening layer of clear material. The short proximal 


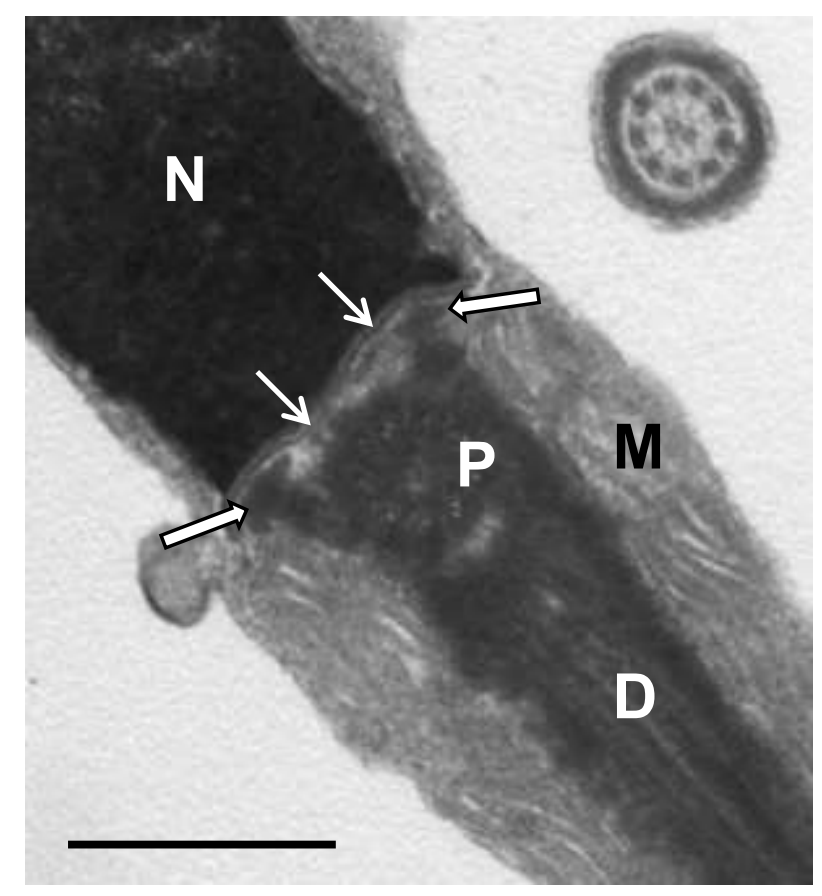

Figure 5. Neck region of a normal emu sperm. Nucleus (N), basal plate (white arrows), capitellum (block arrows), proximal centriole (P), distal centriole (D), mitochondria (M). Note the two shallow impressions representing the implantation fossa and which house elements of the connecting piece. Bar $=0.5 \mu$ m.

centriole lay below the base of the nucleus, was enclosed by the connecting piece and lay on top of, and at right angles to, the long distal centriole. In transverse section, the proximal centriole displayed nine sets of triplet microtubules embedded in a ring of moderately electron dense material (Fig. 5). In longitudinal section it appeared as a hollow, cup-shaped structure with thick walls in which the triplet microtubules were embedded (Fig. 6b). The central cavity of the centriole appeared empty although in some instances it contained fine flocculant material. Mitochondria of the pars spiralis extended into the neck region, lying sandwiched between the plasmalemma and the segmented columns (Fig. 5).

\section{The midpiece:}

The midpiece tapered from the neck region to its termination at the annulus (Figs. 6a,7). The distal centriole lay immediately below the proximal centriole and extended the full length of 


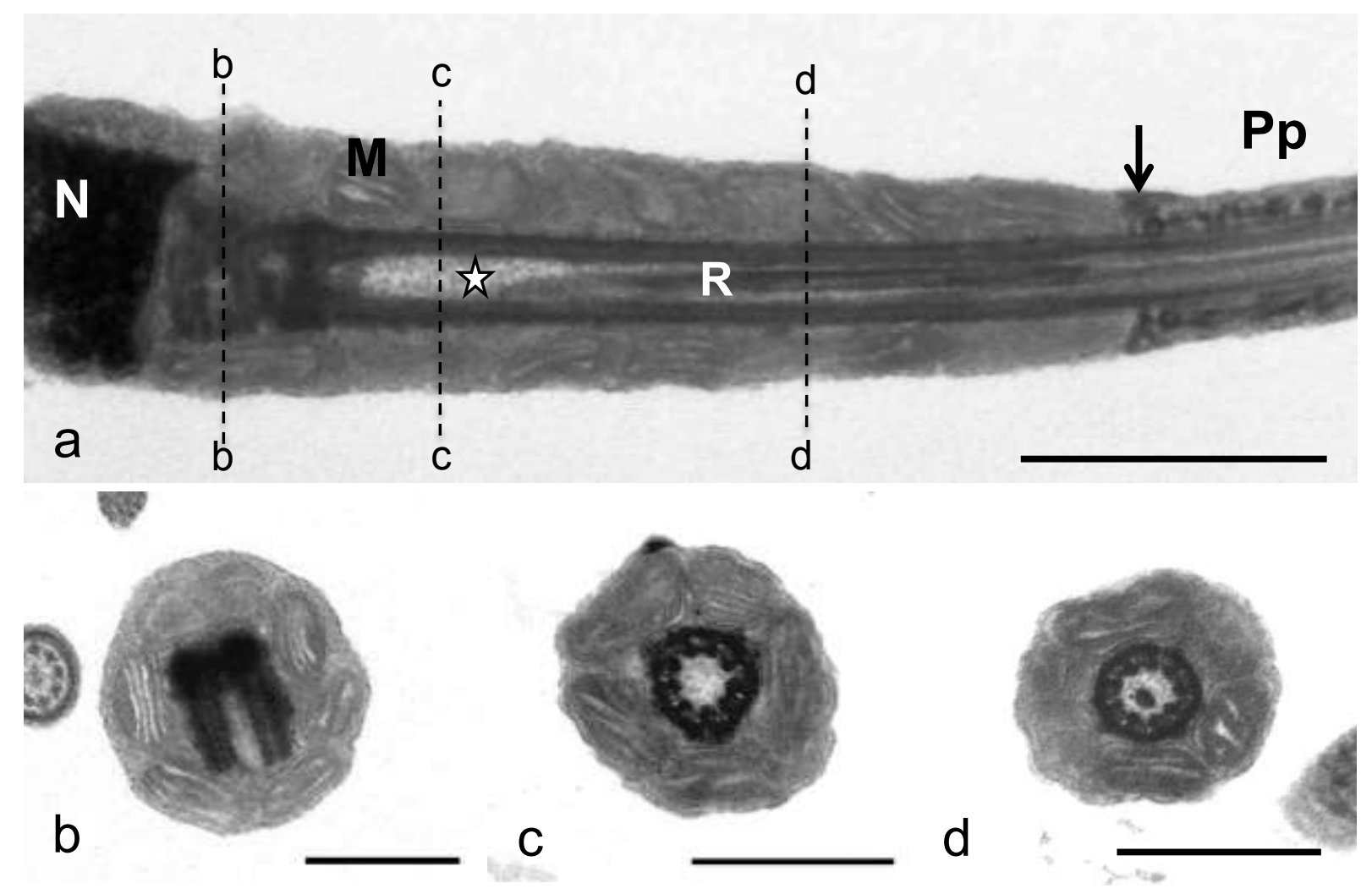

Figure 6. (a) Longitudinal section through the neck and midpiece. Note the long distal centriole which is filled with flocculant material in the anterior region (star), and the rod (R) containing the central pair of microtubules in the posterior segment of the centriole. The annulus (arrow) demarcates the boundary between the midpiece and principal piece. Figs. (b-d) represent equivalent cross-sections of the regions marked b $-\mathrm{d}$ in Fig. 6a. Fig. $6 \mathrm{~b}$ illustrates a section through the proximal centriole, $6 \mathrm{c}$ a section through the anterior aspect of the distal centriole showing the lumen filled with flocculant material and $6 \mathrm{~d}$ a section through the posterior region of the distal centriole with the centrally positioned rod of dense material. Nucleus (N), mitochondria (M), principal piece $(\operatorname{Pp})$. Bar $(\mathrm{a})=1 \mu \mathrm{m} ; \operatorname{Bar}(\mathrm{b}-\mathrm{d})=0.5 \mu \mathrm{m}$.

the midpiece (Figs. 6a, 7). Transverse sections through the anterior segment of the distal centriole revealed a thick electron-dense wall containing nine sets of triplet microtubules (Fig. 6c). The centriolar lumen generally appeared empty in this part of the midpiece, although in some instances granular/flocculant material, similar to that seen in the proximal centriole, was observed (Fig. 6a). In transverse sections through the posterior segment of the 


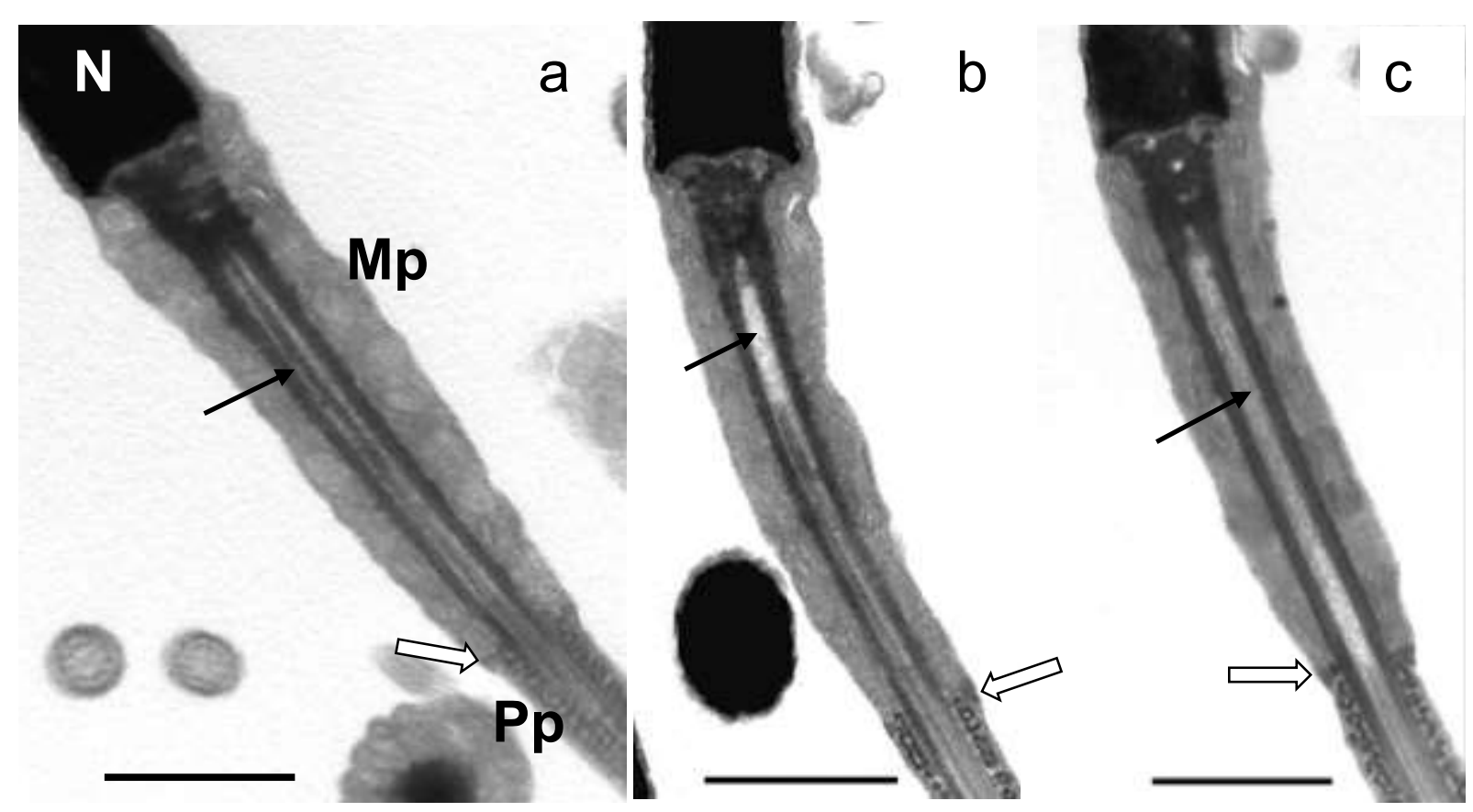

Figure 7. Longitudinal sections through the neck and midpiece. Note in (a) the rod of dense material (arrow) running the complete length of the midpiece. In (b) the lumen of the anterior part of the distal centriole appears empty (arrow) with the rod of dense material only occupying the posterior two thirds of the centriolar lumen. In (c) the lumen of the entire centriole appears empty (arrow). The annulus (open arrows) in (a) and (b) is indistinct, while in $(\mathrm{c})$ it is slightly more pronounced. Nucleus $(\mathrm{N})$, midpiece $(\mathrm{Mp})$, principal piece $(\mathrm{Pp}) . \mathrm{Bar}=$ $1 \mu \mathrm{m}$.

distal centriole, a rod of dense material containing two free microtubules was evident. This rod was generally centrally placed within the centriolar lumen (Fig. 6d) although in some cells it adopted an eccentric position. The eccentric positioning would explain why in some longitudinal sections the lumen of the distal centriole appeared empty (Fig. 7c). In a few instances the rod appeared to extend the full length of the distal centriole (Fig. 7a). From its point of origin, which was variable within the distal centriolar lumen, the rod extended the full length of the midpiece to terminate just above the annulus. The two free microtubules, however, continued caudally as the central pair of microtubules of the axoneme (Figs. 6a,7b, $8 \mathrm{a}, \mathrm{c})$. 

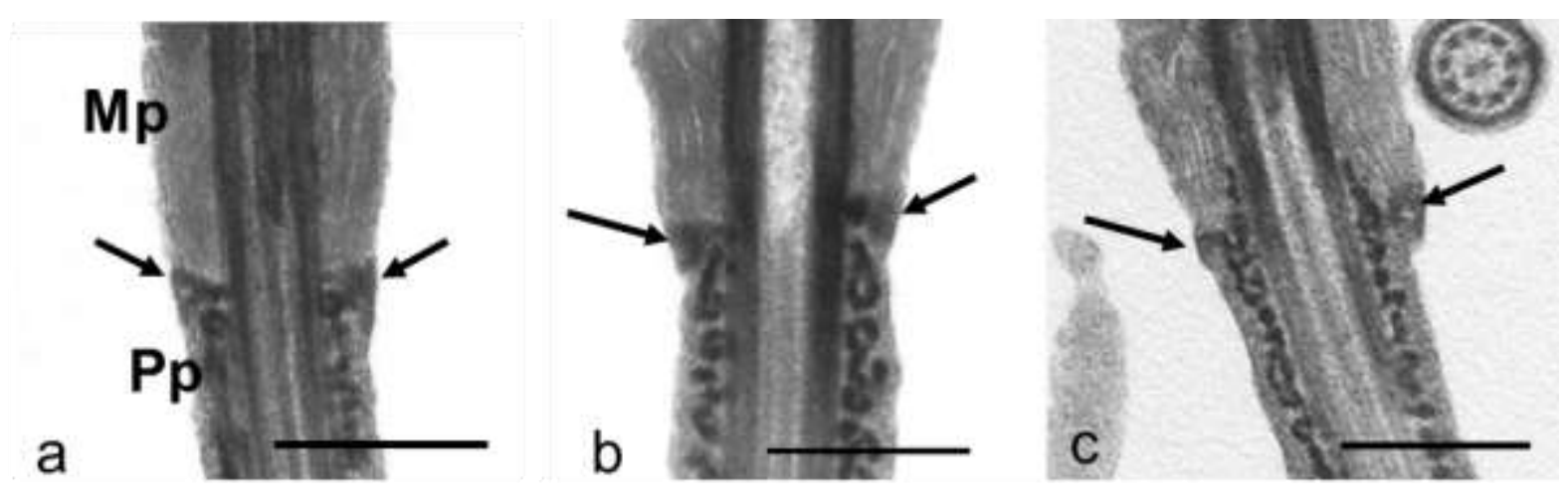

Figure 8. Transition between the midpiece $(\mathrm{Mp})$ and the principal piece $(\mathrm{Pp})$. Note the relatively inconspicuous annulus (arrows) and (a) the positioning of elements of the fibrous sheath beneath the annulus, (b) between the annulus and distal centriole and (c) between the mitochondria of the midpiece and the distal centriole. Bar = $0.5 \mu \mathrm{m}$.

The distal centriole was bordered peripherally by the mitochondria of the pars spiralis. In longitudinal sections seven to eight mitochondrial profiles could be seen running the entire length of the midpiece and into the neck region (Fig. 6a), while in most transverse sections of the midpiece five to six mitochondria could be discerned (Figs. 6b-d). This gave an approximate number of 40 mitochondria forming the mitochondrial sheath. The mitochondria were closely packed and mostly rectangular in form with parallel cristae, although some round forms were observed. There appeared to be no inter-mitochondrial cement present.

The midpiece terminated at the poorly-developed annulus. This structure formed an indistinct band or ring of moderately electron-dense material that demarcated the boundary between the midpiece and the principal piece of the flagellum (Figs. 7,8). The annulus abutted the last row of mitochondria and extended approximately halfway, and in some sperm all the way (Fig.7c) between the plasmalemma and the outer microtubular doublets of the axoneme. In some instances elements of the fibrous sheath of the principal piece were observed interposed between the annulus and the axoneme (Fig. 8b) or even between the mitochondria of the pars 
spiralis and the axoneme (Fig. 8c). However, in a small number of sperm, the annulus was relatively well-developed and filled the space between the plasmalemma and the axoneme. No retro-annular recess was observed in mature sperm.

\section{The principal piece:}

The long principal piece consisted of the axoneme surrounded by an electron-dense, ribbed fibrous sheath. The axoneme displayed the typical structural features previously recorded for the ostrich [13] and was composed of nine regularly spaced outer doublet microtubules surrounding a central pair of single microtubules. In transverse section the A subunit of each doublet exhibited a circular profile and was filled with dense material, whereas the B subunit formed an incomplete lucent cylinder attached to subunit A (Figs. 9, 10a). Dynein arms were seen projecting in a clockwise direction from the A microtubule towards subunit B of the neighbouring doublet. Radial spokes connected the peripheral doublets to the central pair of microtubules and could be clearly discerned in both transverse (Figs. 9, 10) and longitudinal (Fig. 11a) sections of the principal piece.

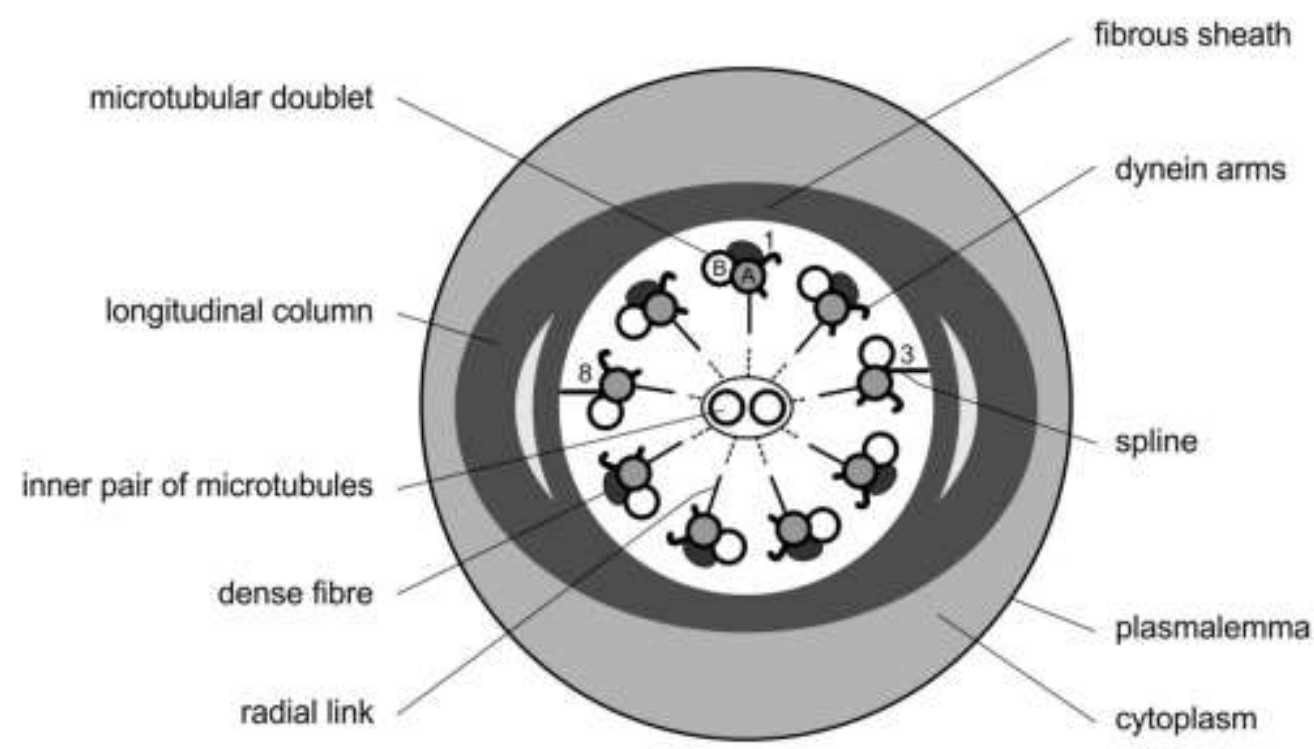

Figure 9. Schematic diagram showing the various components of the proximal part of the principal piece. 


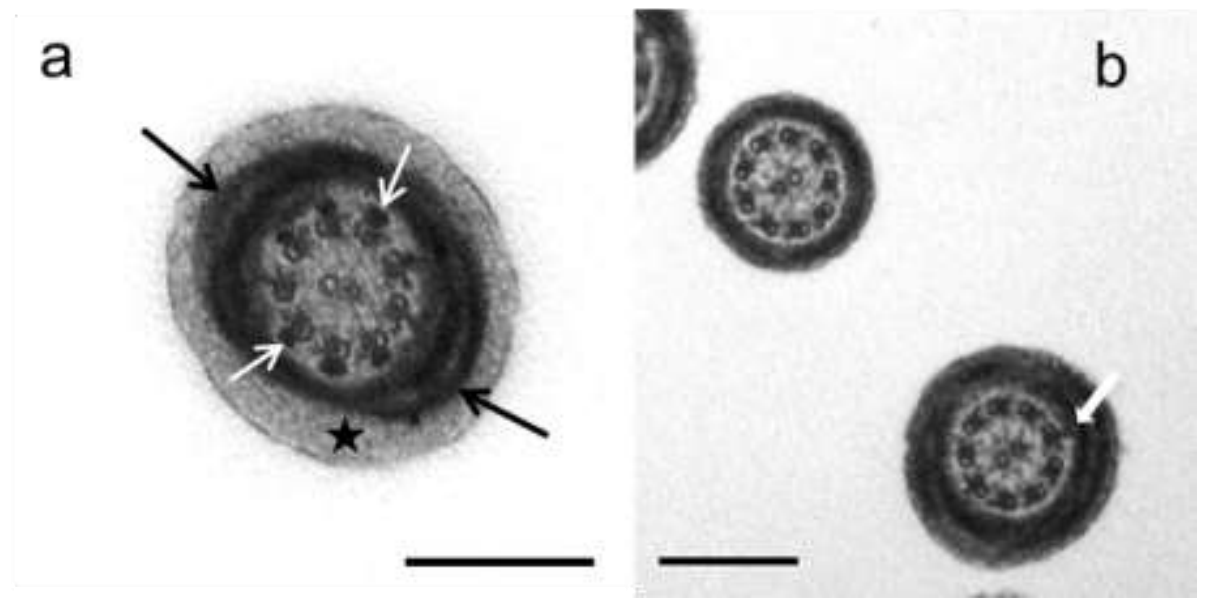

Figure 10. Transverse sections through the proximal (a) and distal (b) segments of the principal piece. Note the difference in diameter [particularly of the distal segment shown in (b)], the laminated longitudinal columns (black arrows) joined by ribs, the various components of the axoneme and in (a) the small dense fibres (white arrows) associated with the doublet microtubules as well as the layer of cytoplasm (star) present between the plasmalemma and fibrous sheath. In (b) the spline connecting one of the doublets to the fibrous sheath is indicated (white arrow). Bar $=0.25 \mu \mathrm{m}$.

The principal piece could be divided into two regions based on structural peculiarities and differences in diameter. The first (proximal) region lay immediately beneath the annulus, was relatively short and was approximately $0.5 \mu \mathrm{m}$ in diameter. The fibrous sheath consisted of two poorly defined longitudinal columns lying in line with the central pair of axonemal microtubules, although this arrangement was not obvious in all the cells studied. The columns, when present, manifested as discrete, broad thickenings of the fibrous sheath which gave the principal piece in transverse sections a laminated appearance (Figs. 9, 10). Although the columns themselves were not always obvious, their position could be determined by the presence of a small septum-like extension of the columns linking them to the adjacent microtubular doublets (doublets 3 and 8) (Fig. 9). The columns were connected by flimsy rib-like structures (Fig. 11b) which in some transverse sections also appeared laminated. Due to the relatively loose, composite arrangement of the fibrous sheath in this region, it sometimes appeared as a multi-layered structure in longitudinal sections of the tail (Fig. 11a). 

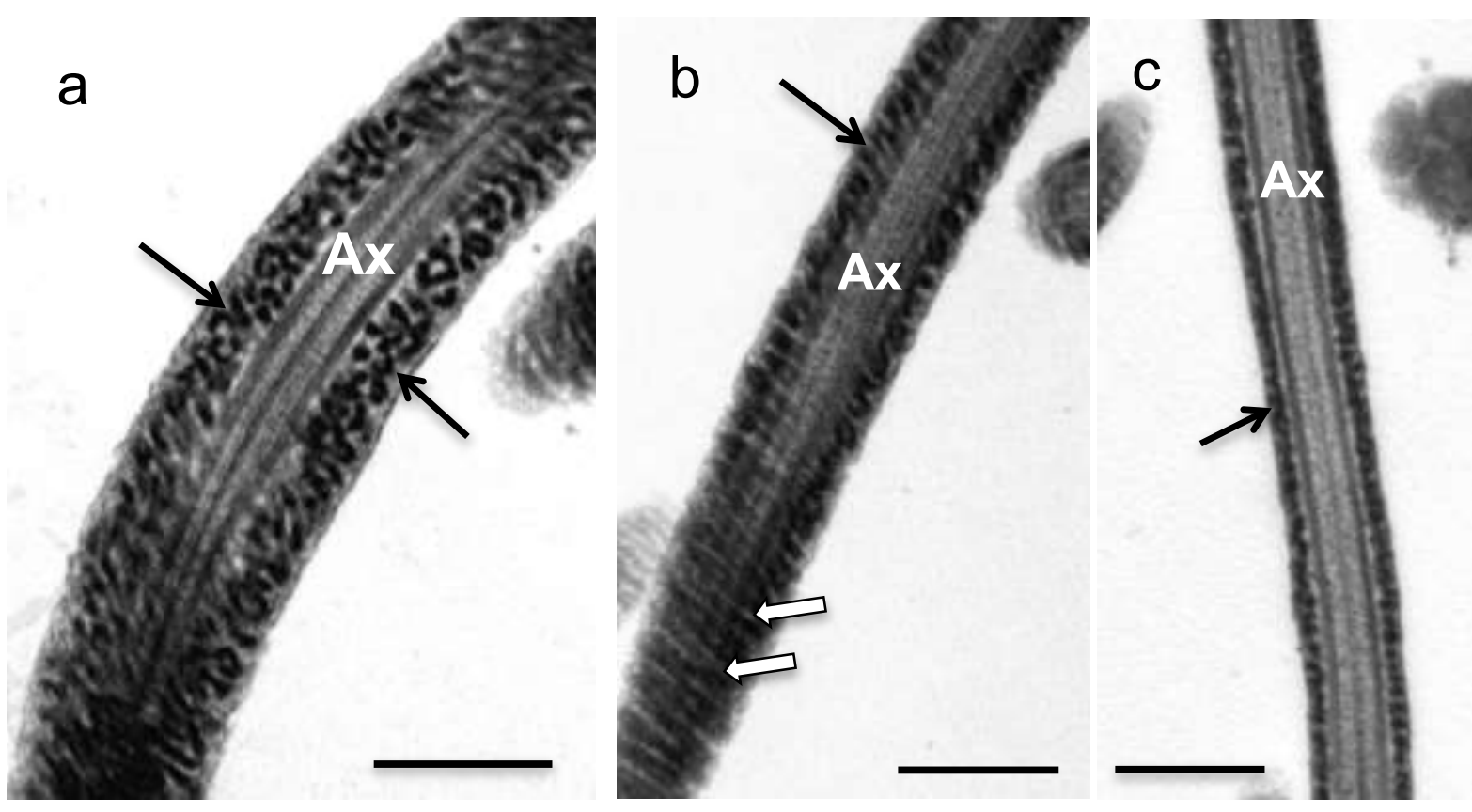

Figure 11. Longitudinal sections of the principal piece showing regional differentiation. In (a) the fibrous sheath in the region just beneath the annulus appears multi-layered (arrows). Note the outer and central microtubules of the axoneme (Ax) connected by evenly-spaced radial spokes. (b) Proximal principal piece. The connecting ribs are illustrated in oblique (arrow) and longitudinal (white arrows) section. In (c) the fibrous sheath of the distal principal piece (arrow) is markedly thinner and tightly covered by the plasmalemma. Bar $=0.5 \mu \mathrm{m}$.

A layer of cytoplasm, composed of fine flocculant material, was present between the fibrous sheath and plasmalemma (Fig. 10a). Another notable feature of this region was the presence of nine small outer dense fibres positioned between the fibrous sheath and the axonemal doublets. Each dense fibre was closely associated with its corresponding doublet (Figs. 9, 10). Dense fibres 3 and 8 were lost a short distance beneath the annulus and replaced by a discrete projection (spline) of material emanating from the longitudinal columns. It was clear from the relative scarcity of transverse sections of the principal piece demonstrating the dense fibres that they only occupied a short segment of the anterior region of this part of the tail.

The second (distal) and longest region of the principal piece was markedly thinner in diameter (approximately $0.3 \mu \mathrm{m}$ ) and tapered gradually towards the endpiece. The fibrous 
sheath was thinner and more compact, the longitudinal columns were no longer present or were poorly developed and the plasmalemma lay closely apposed to the fibrous sheath (Figs. 10b, 11c). The axoneme displayed the characteristic structure although the spline of dense material linking doublets 3 and 8 to the fibrous sheath was often poorly developed or absent.

\section{The endpiece:}

The flagellum terminated in a short endpiece essentially composed of the axoneme covered by the plasmalemma. The fibrous sheath sometimes terminated evenly at the transition between the principal piece and endpiece (Fig. 12a), but generally ended in a staggered fashion (Fig. 12b). The organized arrangement of the axoneme was disrupted along the length of the endpiece with separation of the microtubular doublets being observed as well as loss of the dynein arms and radial spokes. A random decrease in the number of microtubules, most of which were electron-lucent, was obvious towards the termination of the endpiece (Fig. 12
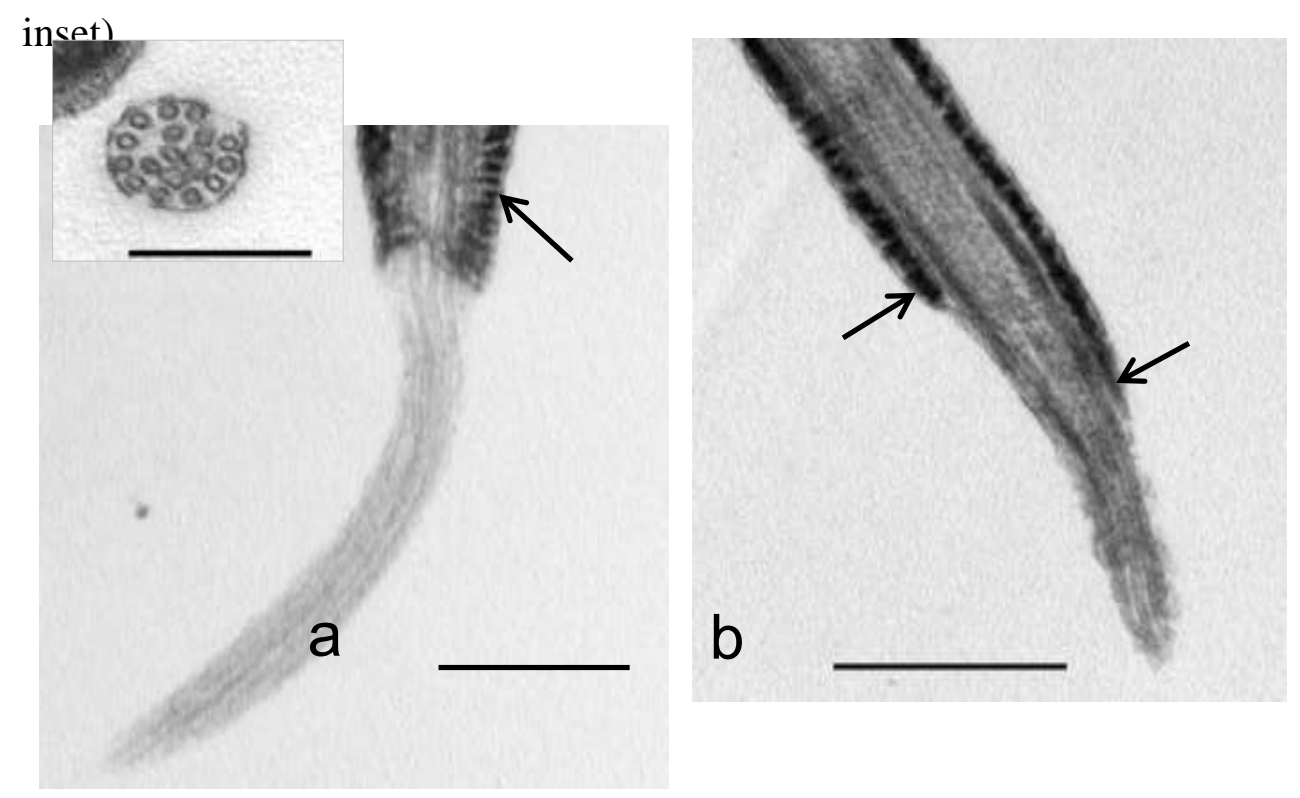

Figure 12. Longitudinal sections through the endpiece of the flagellum. In (a) note the continuation of the axonemal microtubules (arrow) from the principal piece into the endpiece. The inset demonstrates a transverse section of the endpiece containing 15 electron lucent microtubules. In (b) the staggered termination of the fibrous sheath can clearly be seen (arrows). $\mathrm{Bar}=0.5 \mu \mathrm{m}$; inset $\mathrm{Bar}=0.25 \mu \mathrm{m}$. 


\section{Discussion}

Compared to conventional light microscopy, electron microscopy is an expensive and timeconsuming technique which clearly cannot be utilised for the routine assessment of sperm morphology. However, the higher resolution of this imaging technique allows for a more accurate appraisal of sperm morphology thus definitively establishing normal structure. The value of SEM in forming a three dimensional image and of TEM in identifying specific structural features, has been recognized in the evaluation of sperm morphology [17]. These two techniques, together with light microscopy, complement and support each other thus providing essential baseline information relevant to structural studies.

\section{Scanning Electron Microscopy}

The SEM data of Baccetti et al. [12] provides little information on the surface morphology of emu sperm other than to note the length of the various segments of the cell and that the midpiece is not as "deeply marked as in the ostrich". The current study, in addition to clearly revealing the various components of the sperm, demonstrated a distinct difference in cell surface characteristics between the acrosome (smooth) and the rest of the head (nucleus) which appeared mottled. This was particularly obvious using high resolution SEM. This phenomenon would seem to indicate that the surface properties of the plasmalemma overlying the acrosome differ from that part of the cell membrane covering the nucleus. The head of ostrich sperm has also been described as being smooth compared to the rest of the cell $[12,14]$. Whereas the tip of the emu sperm head appears relatively pointed on LM [16], SEM demonstrated that it was blunt, particularly in comparison to that of the ostrich [14]. The most striking surface feature of the emu sperm head was the presence of a cytoplasmic appendage situated in the region of the head base. This structure has not been described in any avian sperm and was not identified by Baccetti et al. [12] in the emu although it was a 
consistent feature of all the birds in the present study. The possible origin of this structure is discussed below.

The midpiece of emu sperm is described by Baccetti et al. [12] as being "marked" when viewed by SEM, which presumably indicated the presence of the mitochondrial sheath in this region. Mitochondrial profiles were clearly visible in the present study when viewed by high resolution SEM as was the ring-like annulus separating the midpiece from the principal piece of the tail. Likewise, the principal piece displayed the ribs of the fibrous sheath lying beneath the plasmalemma whereas the endpiece appeared smooth. Baccetti et al. [12] did not elaborate on the surface features of these parts of the tail in either the emu or ostrich, presumably due to limitations in the methodology used. It was therefore clear from the present study that high resolution SEM provides greater morphological detail than merely distinguishing the various components of the cell.

\section{Transmission Electron Microscopy}

The acrosome is a small conical structure at the tip of the emu sperm head, similar to that described in the ostrich $[12,13]$ and rhea [18]. However, when viewed in sagittal section, the apical tip of the acrosome in the emu displayed a more rounded profile than the sharper tip described for the ostrich and rhea. In common with other ratites the nuclear rostrum in emu sperm extends deep within the acrosome, resulting in the lateral profiles of the acrosome thinning towards the acrosome-nuclear shoulder. The acrosome of the budgerigar, parrots and cockatiel, although also conical in form, does not form a cap over the tip of the nucleus as described in ratites, but ends adjacent to the nucleus without overlapping it [19-21]. Not all non-passerines have a cap-like acrosome, for example, in the white-naped crane [22], jacana [23] and woodpecker [24], a small spherical, button-like acrosome has been described which 
nestles at the blunt apex of the nucleus. These species are considered to be advanced nonpasserines on the basis of DNA studies [25]. It is also noteworthy that they do not possess a perforatorium or endonuclear canal, as in the emu (see below). The sub-acrosomal space in the emu, other ratites and the tinamou is limited due to the intrusion of the nuclear rostrum beneath the acrosome. A similar situation is also apparent in members of the Columbiformes [26]. However, in most other non-passerine birds, for example, the chicken [27,28], goose [29], turkey [30] and duck [31], the sub-acrosomal space present between the acrosome and the perforatorium, is much wider.

The sperm of most non-passerine birds display a prominent fibrous structure, the perforatorium, which is partially lodged within a shallow invagination (the endonuclear canal) of the apical nuclear membrane and partially covered anteriorly by the acrosome $[19,23,26,27,32-35]$. The extent to which the perforatorium pushes beneath the acrosome differs between species. In some galliform birds, such as the chicken, it extends approximately halfway beneath the acrosome, whereas in the turkey [30], duck [31] and white-necked crane [22] the perforatorium is comparatively short and limited to the posterior aspect of the acrosome. In the budgerigar [19] and parrots [20], it is an extremely long structure, extending almost the full length of the sub-acrosomal region. The situation in palaeognaths is strikingly different. In the tinamou the endonuclear canal is a slim, centrally positioned, tube-like structure that extends the complete length of the nucleus [36], whereas in the ostrich $[12,13]$ and rhea [18] it is shorter and only extends part of the way into the nucleus. The endonuclear canal is filled with moderately electron dense material analogous to the perforatorium of neognaths. The present study confirmed that neither an endonuclear canal nor rod-like perforatorium is present in emu sperm. The thin bundle of microfilaments recognised in the apical sub-acrosomal space by Baccetti et al. [12] in the emu and reported 
to represent a reduced extranucler perforatorium was never observed in this study, although flocculant material was often present in the sub-acrosomal space. A typical perforatorium, therefore, appears to be absent in emu sperm. This situation is not unique to the emu as there are some non-passerine species that lack a perforatorium, for example, the woodpecker [24] and jacana $[23,26]$. These species characteristically display a button-like acrosome and not the conical acrosome associated with a nuclear rostrum typical of the palaeognaths.

According to some authors $[30,37]$, the diminishing length and ultimate disappearance of the perforatorium may be indicative of an advancing evolutionary trend. Within this context it is tempting to ascribe phylogenetic significance to the degree of development of the perforatorium in palaeognaths. This argument would place the tinamou (with a long rod-like perforatorium) in a basal position followed by the ostrich and rhea (with a shorter rod-like perforatorium), with the emu, which lacks a perforatorium, representing the most advanced member of this assemblage. The absence or presence of a perforatorium in cassowary and kiwi sperm would provide interesting supplementary information relevant to this question. The actual function of the perforatorium remains unclear [30,34]. Baccetti et al. [34] suggest that it may act as a support for the acrosome, although this clearly would not be the case in ratites where the perforatorium is entirely enclosed within the nucleus. The identification of actin filaments within the avian perforatorium [34,38] may indicate a role in sperm penetration of the ovum although this function has not been demonstrated.

The consistent presence of a thread-like appendage near the base of the nucleus confirmed by SEM and TEM, and also readily recognised by LM [16] has not previously been described in any other bird sperm. It is unclear why this structure was not identified by Baccetti et al. [12] in the emu although this study examined sperm isolated from the testis in contrast to the 
sperm collected from the distal deferent duct in the present study. The cytoplasmic features of the appendage would suggest that it represents a small remnant of residual cytoplasm resulting from the release of the mature sperm from the surrounding Sertoli cells during spermiation. The efficient removal of most of the residual cytoplasm from emu sperm is supported by the fact that cytoplasmic droplets are rarely observed in emu semen samples [39]. However, the close positioning of cytoplasmic bridges to the location of the thread-like appendage during spermiogenesis may also point to their involvement in the origin of the appendage [40].

The neck and midpiece of ratite sperm, in common with that of non-passerine birds, extends from the base of the head to the annulus. The neck region of emu sperm has not previously been described and was shown in the present study to contain mitochondria of the pars spiralis and the proximal centriole surrounded by the components of the connecting piece (segmented columns and capitellum) as in the ostrich [13] and rhea [18]. The segmented appearance of the columns is more pronounced in the emu than in the other two species. A common feature of ratite sperm, including the emu, is the presence of shallow, twin implantation fossae separated by a nuclear projection (Fig. 1a) [13,18,present study]. The implantation fossa of other non-passerine birds is also described as being shallow [26] but is formed by a single concave depression of the nuclear base, as seen for example in the domestic chicken $[27,30]$ and duck [41].

A characteristic feature of ratite sperm is the presence of a long distal centriole which runs almost the entire length of the midpiece. It has been described in the ostrich $[12,13]$, rhea [18], tinamou [36] and emu [12,present study] and lies perpendicular to the proximal centriole. In other non-passerines such as the chicken [28], duck [33,41], turkey [30] and 
budgerigar [19], the distal centriole is restricted to the anterior region of the midpiece. In contrast to the situation in the ratites, the axoneme in those species with a shorter distal centriole is already present in the posterior part of the midpiece, together with the nine outer dense fibres (see below). In the emu, as in the ostrich [13], the lumen of the initial (anterior) part of the distal centriole, just beneath the proximal centriole, generally appeared empty or contained flocculant material. This phenomenon was also observed by Baccetti et al. [12]. The posterior centriolar lumen was occupied by a rod of moderately electron-dense material which contained two longitudinally disposed microtubules. The microtubules were continuous, in the vicinity of the annulus, with the central pair of axonemal microtubules as also described for the ostrich [13], rhea [18] and tinamou [36]. In the rhea the central microtubules do not appear to be embedded in a rod of dense material [18].

The present study confirmed the previous observation [12] regarding the high number (40 or more) of tightly compacted mitochondria present in the emu sperm midpiece although the small amount of inter-mitochondrial cement described by Baccetti et al. [12] was not observed. The ostrich and rhea both have fewer mitochondria (20-25 and 30 respectively) $[12,13,18]$ despite midpiece length being similar in each of the three ratites. This variation in number can be attributed to either the mitochondria in the emu being smaller than those of other ratites, or to the absence of inter-mitochondrial cement in the emu, which is present in both the ostrich [13] and rhea [18]. Similarly, the tinamou also has fewer mitochondria in the midpiece as well as inter-mitochondrial cement [36]. Other non-passerines such as the chicken [30], turkey [30,42], duck [41] and guinea fowl [30] also have fewer mitochondria (25-30) in the midpiece when compared to the emu, despite midpiece length being similar. However, inter-mitochondrial cement appears to be absent in the midpiece of these birds. It has been reported that in promiscuous birds the midpiece contains many more mitochondria 
than the same region in monogamous birds [43], purportedly to propel the longer tail in these species. As tail lengths in the emu, ostrich and rhea are similar [16] and these species are described as monogamous [1,2], this link would appear tenuous for the emu.

The annulus, demarcating the boundary between the midpiece and principal piece, appears to be present in most non-passerine birds, including the ratites, although it is reportedly absent in the tragopan [26]. In contrast to the well-developed structure described by Baccetti et al. [12] and Soley [13] in the ostrich, the annulus was not prominent in TEM sections of emu sperm. However, with the use of low voltage high resolution SEM, the ring-like nature of the annulus was particularly obvious in uncoated emu sperm samples. An appreciation of the morphology of the annulus may be important considering the reported observation of changes in the structure of the annulus during the formation of biflagellate sperm in the drake [44].

The small, dense fibres associated with the doublets in the proximal region of the principal piece of emu sperm [12, present study] are also present as rudimentary dense fibres in the ostrich [13] and rhea [18]. It was originally reported [36] that dense fibres were absent in tinamou sperm, but later confirmed that they were present in the proximal region of the principal piece [45]. In other non-passerines such as the chicken [27,28], duck [41], turkey [30] and guinea fowl [35], similar dense fibres have been observed. In these birds the dense fibres are more conspicuous and are detected in the distal part of the midpiece at the point caudal to the termination of the distal centriole. In the phylogenetically more advanced passerine birds the fibres are large, uniform in shape [45] and present throughout the flagellum. They also appear in reptiles [26] as poorly developed fibres, whereas in mammals they are pronounced with each fibre displaying a distinctive form and extending the entire length of the principal piece [46-48]. The outer dense fibres of ratite sperm thus appear to be 
rudimentary when compared to the sperm of other vertebrates and of little functional significance. Again, it is tempting to speculate that the evolutionary trend favours the development of larger outer dense fibres in vertebrate sperm, although Jamieson [26] dismisses the use of this feature for the determination of phylogeny.

As is the case with mammalian sperm (Fawcett, 1975; Olsen et al., 1976b)[48,49], the fibrous sheath of the ratite principal piece begins immediately caudal to the annulus and extends posteriorly for most of the length of the flagellum, terminating just proximal to the endpiece. In both the mammalian and ratite flagellum, the sheath consists of a two sets of circumferentially orientated ribs linked by two longitudinal columns running the length of, and on opposite sides (in line with doublets 3 and 8) of the principal piece. These longitudinal columns are prominent structures and run for most of the length of the principal piece in mammals $[48,49]$. In contrast, in ratites the columns although not referred to as such by all authors) appear to be rudimentary as indicated by their relatively flimsy nature and laminated appearance $[12,13,18,36$,present study]. The ribbed fibrous sheath was particularly obvious with high resolution SEM as well as in longitudinal and transverse sections of the principal piece examined by TEM. A typical ribbed fibrous sheath is absent in other nonpasserine birds $[27,30,41,50]$, and is replaced by an amorphous sheath of moderate electrondensity with no specific structural detail. The termination of the axoneme at the endpiece of the flagellum in the emu followed the general vertebrate pattern with a random decrease in the number of axonemal microtubules as previously described in the ostrich [13]. According to Baccetti et al. [12] the end part of the tail contains the "basic " $9+2$ " axoneme" " but, based on the present study, this is only true for the initial part of the endpiece immediately after the termination of the principal piece. 
From a practical perspective, the present ultrastructural study on emu sperm harvested from the distal ductus deferens of sexually mature birds provided a more accurate description and pictorial record of normal sperm ultrastructure compared to the previous study based on testicular material [12]. In addition to broadly confirming the basic ultrastructural characteristics described for emu sperm by Baccetti et al. [12], this study revealed some previously unreported morphological features. These included distinct differences in surface properties between the acrosome and nucleus, the presence of a thread-like appendage near the base of the nucleus, variable positioning of the annulus relative to structures located at the midpiece - principal piece junction and regional differentiation of the principal piece. This detailed ultrastructural description will facilitate a more accurate assessment of sperm anomalies in this species. Of academic interest was the observation that emu sperm, although displaying similar basic morphological features to sperm of other ratites and the tinamou, demonstrated marked structural peculiarities, notably the lack of an endonuclear canal and a perforatorium. The tip of the acrosome is also more rounded in emu sperm. Moreover, there were significantly more mitochondria present in the midpiece of emu sperm coupled with an absence of inter-mitochondrial cement. Whereas the broad morphological features of emu sperm outlined above would appear to add credence to the general view that the ratites, together with the tinamous, form a monophyletic group at the base of the avian phylogenetic tree [51-53], it is also clear that emu sperm are distinctly different from those of the ostrich, rhea and tinamou which together share morphological affinities [12-14,18,26,36,45]. This observation may lend some support to the alternate view [54] that the Australasian ratites represent a separate clade that developed independently from flightless ancestors. 


\section{Acknowledgements}

The authors thank Mr P. Bezuidenhout, Chairman of the Eastern Cape Emu Breeders Association and Mrs P. Rough for making material available and the Grahamstown Ostrich Abattoir and Emu Ranch, Rustenburg, Northwest Province, South Africa for use of their facilities.

\section{References}

[1] Malecki IA, Cummins JM, Martin GB, Lindsay DR. Effect of collection frequency on semen quality and the frequency of abnormal forms of spermatozoa in the emu. P Aus S Anim 1998;22:406.

[2] Malecki IA, Beesley J, Martin GB. Changes in the characteristics of emu sperm with season. Brit Poultry Sci Suppl 2000;41:S18.

[3] Malecki IA, Rybnik PK, Martin GB. Artificial Insemination technology for ratites: a review. Aust J Exp Agr 2008;48:1284-92.

[4] Cloete SWP, Brand TS, Hoffman L, Brand Z, Engelbrecht A, Bonato M, Glatz PC, Malecki IA. The development of ratite production through continued research. World Poultry Sci J 2012;68:323-33.

[5] King, L.M., Holsberger, D.R. \& Donoghue, A.M. Correlation of CASA velocity and linearity parameters with sperm mobility phenotype in turkeys. J Androl 2000;21:65-71.

[6] Foote, R.H. The history of artificial insemination: Selected notes and notables. J Anim Sci 2002;80:1-10. 
[7] Łukaszewicz, E. Artificial insemination in geese. World Poultry Sci J 2010;66:647-58.

[8] Gee GF, Bertschinger H, Donoghue AM, Blanco J, Soley JT. Reproduction in nondomestic birds: Physiology, semen collection, artificial insemination and cryopreservation. Avian Poult Biol Rev 2004;15:47-101.

[9] Minnaar P, Minnaar M. The Emu farmer's handbook $5^{\text {th }}$ edition. Texas: Induna Company; 1994.

[10] Blanco JM, Wildt, DE, Höfle U, Voelker W, Donoghue AM. Implementing artificial insemination as an effective tool for ex situ conservation of endangered avian species. Theriogenology 2009;71:200-13.

[11] Soley JT. Transmission electron microscopy of ostrich (Struthio camelus) sperm. Proc Electron Microsc Soc South Afr 1989;19:145-6.

[12] Baccetti B, Burrini AG, Falchetti E. Spermatozoa and relationships in paleognath birds. Biol Cell 1991;71:209-16.

[13] Soley JT. Ultrastructure of ostrich (Struthio camelus) spermatozoa: I. Transmission electron microscopy. Onderstepoort J Vet Res 1993;60:119 -30.

[14] Soley JT, Roberts DC. Ultrastructure of ostrich (Struthio camelus) spermatozoa: II. Scanning electron microscopy. Onderstepoort J Vet Res 1994;61:239-46.

[15] Soley, JT, Groenewald HB. Reproduction. In: Deeming DC, editor. The Ostrich. Biology, Production and Health, New York: CABI Publishing; 1999, p. 129 -58. 
[16] Du Plessis L, Soley JT. Light microscopy of emu (Dromaius novaehollandiae) sperm: preparatory technique, morphological features and morphometry. Theriogenology in press

[17] Du Plessis L, Soley JT. Head-base bending and disjointed spermatozoa in the emu (Dromaius novaehollandiae): a morphological comparison of two closely related defects. Theriogenology 2011;76:1275-83.

[18] Phillips DM, Asa CS. Development of spermatozoa in the rhea. Anat Record $1989 ; 223: 276-82$.

[19] Samour JH, Smith CA, Moore HD, Markham JA. Semen collection and spermatozoa characteristics in budgerigars (Melopsittacus undulates). Vet Rec 1986;118:397-9.

[20] Jamieson BGM, Koehler L, Todd BJ. Spermatozoal ultrastructure in three species of parrots (Aves, Psittaciformes) and its phylogenetic implications. Anat Rec 1995;241:461-8.

[21] Lovas EM, Filippich LJ, Johnston SD. Spermiogenesis in the Australian cockatiel Nymphicus hollandicus. J Morphol 2012;273:1291-305.

[22] Phillips DM, Asa CS, Stover J. Ultrastructure of spermatozoa of the white-naped crane. J Submicr Cytol 1987;19:489-94.

[23] Saita A, Longo OM, Tripepi S. Osservazioni comparative sulla spermiogenesi. III. Aspetti ultrastrutturali della spermiogenesis di Jacana jacana (Charariformes). Accad. Naz. Lincei 1983;74:417-30.

[24] Henley C, Feduccia A, Costello D P. Oscine spermatozoa: A light and electron- 
microscopy study. Condor 1978;80:41-8.

[25] Sibley CG, Ahlquist JE, Monroe BL. A classification of the living birds of the world based on DNA-DNA hybridization studies. Auk 1988;105:409-23.

[26] Jamieson BGM. Avian spermatozoa: Structure and Phylogeny. In: Jamieson BGM, editor. Reproductive Biology and Phylogeny of Birds Part A. Enfield: Science Publishers; 2007, p. 349-511.

[27] Lake PE, Smith W, Young D. The ultrastructure of the ejaculated fowl spermatozoan. Q J Exp Physiol 1968;53:356-66.

[28] Bakst MR, Howarth B. The head and midpiece of cock spermatozoa examined with the transmission electron microscope. Biol Reprod 1975;12:632-40.

[29] Ferdinand A. Licht- und elektronenmikroskopische Untersuc hungen zur Morphologie von Ganterspermatozoen. Dissertation zur erlangung des grades eines Doctor Medicinae Veterinariae. Hannover, 1992.

[30] Thurston RJ, Hess RA. Ultrastructure of spermatozoa from domesticated birds: Comparative study of turkey, chicken and guinea fowl. Scanning Microscopy 1987;1:182938.

[31] Maretta M. The ultrastructure of the spermatozoon of the drake. I. Head. Acta Vet [Czech] 1975;25:47-52. 
[32] Nagano T. Observations on the fine structure of the developing spermatid in the domestic chicken. J Cell Biol 1962;14:193-205.

[33] Humphreys PN. Brief observations on the semen and spermatozoa of certain passerine and non-passerine birds. J Reprod Fert 1972;29:327-36.

[34] Baccetti B, Bigliardi E, Burrini AG. The morphogenesis of vertebrate perforatorium. J Ultrastruct R 1980;71:272-87.

[35] Thurston RJ, Hess RA, Hughes BL, Froman DP. Ultrastructure of the guinea fowl (Numidia meleagris) spermatozoan. Poultry Sci 1982;61:1738-43.

[36] Asa C, Phillips DM, Stover J. Ultrastructure of spermatozoa of the crested tinamou. J Ultra Mol Struct R 1986;94:170-5.

[37] Jamieson BMG, Hodgson A, Spottiswood CN. Ultrastructure of the spermatozoon of Myrmecocichla formicivora (Vieillot, 1881) and Philetairus socius (Latham, 1790) (Aves; Passeriformes), with a new interpretation of the passeridan acrosome. Acta Zool 2006;87:297-304.

[38] Campanella C, Gabbiani G, Baccetti B, Burrini AG, Pallini V. Actin and myosin in the vertebrate acrosomal region. J Submicr Cytol 1979;11:53-71.

[39] Du Plessis L, Soley JT. Incidence, structure and morphological classification of abnormal spermatozoa in the emu (Dromaius novaehollandiae). Theriogenology 2011;75: 589-601. 
[40] Du Plessis, L. The morphology and development of normal and abnormal spermatozoa in the emu, Dromaius novaehollandiae. PhD Thesis, University of Pretoria, Pretoria, 2013.

[41] Maretta M. The ultrastructure of the spermatozoon of the drake. II. Tail. Acta Vet [Czech] 1975;25:53-60.

[42] Bakst MR. Ultrastructure of chicken and turkey gametes, fertilization and oviductal sperm transport: a review. $9^{\text {th }}$ Int Congr Anim Reprod Artif Insem, Madrid. 1980; Volume II: 511-517.

[43] Johnson DDP, Briskie JV. Sperm competition and sperm length in shorebirds. Condor 1999;101:848-54.

[44] Maretta M. Ultrastructure of double and multiple sperm tails in drakes. Vet Med [Czech] 1979;24:679-89.

[45] Asa CS, Phillips DM. Ultrastructure of avian spermatozoa: A short review. In: Mohri H, editor. New Horizons in Sperm Cell Research, New York: Gordon and Breach Science Publishers; 1987, p. 365-73.

[46] Fawcett DM, Phillips DW. Recent observations on the ultrastructure and development of the mammalian spermatozoon. In: Baccetti B, editor. Comparative Spermatology, New York: Academic press; 1970, p.13-28.

[47] Phillips DM. Spermiogenesis. London: Academic Press; 1974. 
[48] Fawcett DW. The mammalian spermatozoon. Dev Biol 1975;44:394-436.

[49] Olsen GE, Hamilton DW, Fawcett DW. Isolation and characterization of the fibrous sheath of rat epididymal spermatozoa. Biol Reprod 1976;14:517-30.

[50] Tingari, M.D. Observations on the fine structure of spermatozoa in the testis and excurrent ducts of the male fowl, Gallus domesticus. J Reprod Fertil 1973;34:255-65.

[51] Stapel SO, Leunissen JAM, Versteeg M, Wattel J, De Jong WW. Ratites as oldest offshoot of avian stem - evidence from $\alpha$-crystallin sequences. Nature 1984;311:257-9.

[52] Cracraft, J. Avian evolution, Gondwana biogeography and the Cretaceous-Tertiary mass extinction event. P Roy Soc Lond B Bio 2001;268:459-69.

[53] Johnston P. New morphological evidence supports congruent phylogenies and Gondwana vicariance for palaeognathous birds. Zool J Linn Soc-Lond 2011;163:959-82.

[54] Harshman J, Braun EL, Braun MJ, Huddleston CJ, Bowie RCK, Chojnowski JL, Hackett SJ, Han K-L, Kimball RT, Marsk BD, Miglia KJ, Moore WS, Reddy S, Sheldon, FH, Steadman DW, Steppan SJ, Witt CC, Yuri T. Phylogenetic evidence for multiple losses of flight in ratite birds. PNAS 2008;105:13462-7. 